This item was submitted to Loughborough's Institutional Repository (https://dspace.lboro.ac.uk/) by the author and is made available under the following Creative Commons Licence conditions.

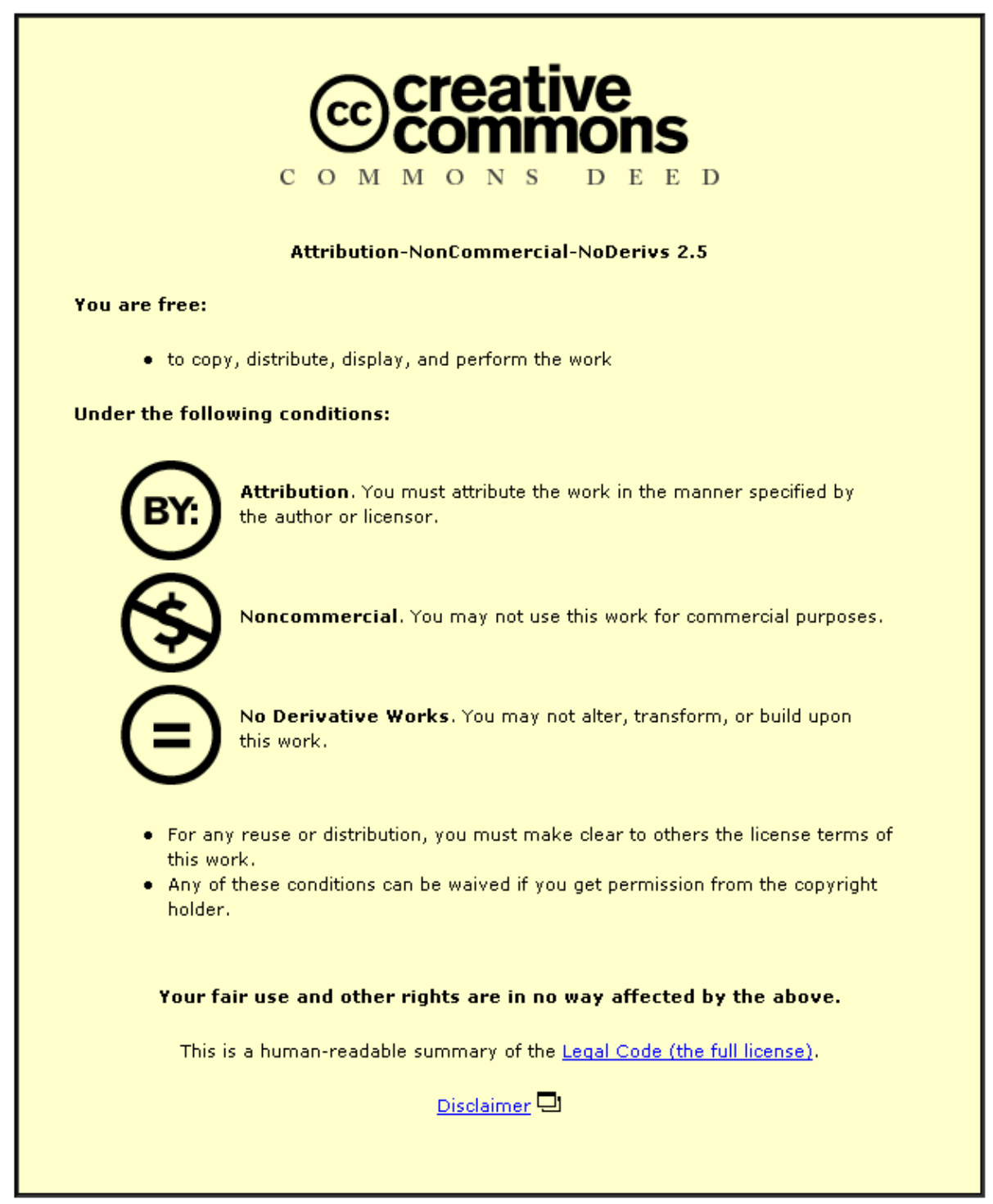

For the full text of this licence, please go to: http://creativecommons.org/licenses/by-nc-nd/2.5/ 


\title{
Influence of a Fed or Fasted State on the s-IgA Response to Prolonged Cycling in Active Men and Women
}

\author{
Judith E. Allgrove, Louise Geneen, Sarah Latif, \\ and Michael Gleeson
}

\begin{abstract}
This study investigated the effect of a fed or fasted state on the salivary immunoglobulin A (s-IgA) response to prolonged cycling. Using a randomized, crossover design, 16 active adults ( 8 men and 8 women) performed $2 \mathrm{hr}$ of cycling on a stationary ergometer at $65 \%$ of maximal oxygen uptake on 1 occasion after an overnight fast (FAST) and on another occasion $2 \mathrm{hr}$ after consuming a 2.2-MJ high-carbohydrate meal (FED). Timed, unstimulated whole saliva samples were collected immediately before ingestion of the meal, immediately preexercise, $5 \mathrm{~min}$ before cessation of exercise, immediately postexercise, and $1 \mathrm{hr}$ postexercise. The samples were analyzed for s-IgA concentration, osmolality, and cortisol, and saliva flow rates were determined to calculate s-IgA secretion rate. Saliva flow rate decreased by $50 \%$ during exercise $(p$ $<.05)$, and s-IgA concentration increased by $42 \%(p<.05)$, but s-IgA secretion rate remained unchanged. There was a $37 \%$ reduction in s-IgA:osmolality postexercise ( $p$ $<.05)$, and salivary cortisol increased by $68 \%(p<.05)$. There was no effect of FED vs. FAST on these salivary responses. The s-IgA concentration, secretion rate, and osmolality were found to be significantly lower in women than in men throughout the exercise protocol $(p<.05)$; however, there was no difference between genders in saliva flow rate, s-IgA:osmolality ratio, or cortisol. These data demonstrate that a fed or fasted state $2 \mathrm{hr}$ before exercise does not influence resting s-IgA or the response to prolonged cycling. Furthermore, these results show lower levels of s-IgA and osmolality in women than in men at rest.
\end{abstract}

Keywords: salivary immunoglobulin A, nutritional status, exercise, gender, saliva flow rate

It is now widely recognized that exercise can have deleterious effects on the immune system (Gleeson, 2007). Prolonged, strenuous exercise can result in a temporary depression of certain aspects of immune function (Mackinnon, 2000), and there is increasing evidence to suggest that athletes engaged in heavy training and competition tend to suffer from a higher incidence of upper respiratory illness

\footnotetext{
Allgrove is with the School of Science, University of Greenwich at Medway, Kent, ME4 4TB, UK. Geneen, Latif, and Gleeson are with the School of Sport and Exercise Sciences, Loughborough University, Loughborough, LE11 3TU, UK.
} 
than their sedentary counterparts (Fahlman \& Engels, 2005; Nieman, Johanssen, Lee, \& Arabatzis, 1990; Peters \& Bateman, 1983; Spence et al., 2007).

Immunoglobulin $\mathrm{A}$ is the predominant antibody present in mucosal fluids and can be measured noninvasively in saliva. Salivary immunoglobulin A (s-IgA) plays an important role in immunity as the first line of defense against potential pathogens invading the oral and nasal cavities and functions by inhibiting the colonization of pathogens, binding antigens for transport across the epithelial barrier, and neutralizing viruses (Lamm, 1998). A reduction in the concentration of s-IgA has been implicated as a causal factor for the reported increased incidence of upper respiratory illness during heavy training in athletes (Fahlman \& Engels, 2005; Gleeson et al., 1999; Neville, Gleeson, \& Folland, 2008). Indeed, several studies have reported significant reductions in s-IgA after an acute bout of intense exercise (Gleeson et al., 1999, Nieman et al., 2002; Steerenberg et al., 1997; Tomasi, Trudeau, Czerwinski, \& Erredge, 1982). However, others have reported significant increases in s-IgA (Allgrove, Gomes, Hough, \& Gleeson, 2008; Blannin et al., 1998; Sari-Sarraf, Reilly, Doran, \& Atkinson, 2007) or no change (Li \& Gleeson, 2004; Mackinnon \& Hooper, 1994; McDowell, Chaloa, Housh, Tharp, \& Johnson, 1991; Walsh et al., 1999). These discrepant findings might be related to several factors including the method of expressing s-IgA, nutritional status of the individual, and the exercise protocol employed.

The saliva flow rate is suggested to play a critical role in oral health via a mechanical washing effect and through the supply of both immune and nonimmune elements into the oral cavity (Li \& Gleeson, 2004; Ranoten \& Meurman, 2000; Tenuvuo, 1998). A decrease in the saliva flow rate has been repeatedly shown after prolonged exercise via mechanisms such as dehydration, autonomic imbalance, and evaporation of saliva through increased breathing (Blannin et al., 1998; Laing et al., 2005; Steerenberg et al., 1997; Walsh et al., 2002). However, a reduced saliva flow rate might artificially increase s-IgA concentration ( $\mathrm{Li} \&$ Gleeson, 2004; Walsh, Bishop, Blackwell, Wierzbicvki, \& Montague, 2002). Consequently, expressing s-IgA as a secretion rate (flow rate $\times$ concentration) or as a ratio to solute concentration (osmolality) might be more valid, because solute secretion rate appears to be unaffected by exercise (Blannin et al.). Indeed, previous studies have shown transient reductions in both the s-IgA secretion rate and s-IgA:osmolality ratio after prolonged cycling (Walsh et al., 2002; Laing et al.).

The responses of s-IgA to exercise are thought to be mediated by increases in circulating stress hormones such as catecholamines and cortisol. Cortisol has been shown to inhibit transepithelial transport of s-IgA in rodents (Sabbadini \& Berczi, 1995) and might inhibit IgA synthesis by B cells in the submucosa (Saxon, Stevens, Ramer, \& Clements, 1978). Salivary cortisol has been shown to correlate highly with circulating levels (Chicharro, Lucia, Perez, Vaquero, \& Urena, 1998), making it a reliable marker of the stress-hormone response to exercise. Nutritional interventions are commonly used by athletes as a method to offset the exerciseinduced immune response (Gleeson \& Bishop, 2000). Carbohydrate (CHO) ingestion during exercise has been shown to attenuate the rise in stress hormones, whereas an athlete exercising in a CHO-depleted state experiences larger increases in circulating stress hormones (Gleeson, Pyne, \& Callister, 2004). However, previous investigations have shown little effect of $\mathrm{CHO}$ ingestion on s-IgA concentration or secretion rate during prolonged exercise compared with placebo (Bishop, 
Blannin, Armstrong, Rickman, \& Gleeson, 2000; Nehlsen-Cannarella et al., 2000; Nieman et al., 2002). In one previous study it was shown that the prior nutritional status (i.e., fed or fasted) of an individual significantly influenced resting s-IgA; higher and more variable levels in s-IgA concentration were observed in fasting participants' saliva than nonfasting participants' saliva (Gleeson, Cripps, Clancy, $\&$ Geraghty, 1990). Moreover, Oliver et al. (2007) reported that $48 \mathrm{hr}$ of energy and fluid restriction resulted in a fall in resting s-IgA secretion rate. However, the precise mechanism of action to explain these differences is currently unclear; whether they are directly related to the meal ingested or hydration status remains to be determined.

The effects of nutritional status (fed vs. fasted) on the s-IgA response to exercise remain unknown. Given the apparent link between s-IgA and nutritional status at rest (Gleeson et al., 1990; Oliver et al., 2007), understanding the impact of this factor on the s-IgA response to exercise could have implications for future research designs, as well as consequences for the oral health of individuals performing strenuous exercise. Therefore, the current study investigated the influence of a fed or fasted state $2 \mathrm{hr}$ before exercise on the s-IgA responses to prolonged cycling. We hypothesized that a fasted state would exacerbate the immunoendocrine response to exercise, resulting in a greater reduction in s-IgA postexercise. Both men and women were recruited to participate in the study; therefore, an additional aim was to assess whether gender would influence the salivary measures.

\section{Participants}

After approval from the university ethical committee, 16 active, healthy adults ( 8 men and 8 women) who were participating in regular physical activity at least three times per week for more than $2 \mathrm{hr}$ /day volunteered to take part in the study. Their physical characteristics are outlined in Table 1. Participants were informed of the aims and procedures of the study before providing written informed consent and completing a comprehensive health questionnaire.

\section{Preliminary Measurements}

Approximately 1 week before the main trials, participants completed a continuous incremental test on an electromagnetically braked cycle ergometer (Lode Excalibur, Groningen, The Netherlands) to volitional exhaustion to determine their

\section{Table 1 Participant Characteristics, $N=16, M(S E M)$}

\begin{tabular}{lcc}
\hline Variable & Men $(\boldsymbol{n}=\mathbf{8})$ & Women $(\boldsymbol{n}=\mathbf{8})$ \\
\hline Age, years & $22(4)$ & $22(1)$ \\
Body mass, $\mathrm{kg}$ & $80.6(5.8)$ & $60.0(0.9)^{*}$ \\
$\mathrm{Height}, \mathrm{cm}$ & $182(1)$ & $165(1)^{*}$ \\
$\mathrm{VO}_{2 \max }, \mathrm{ml} \cdot \mathrm{kg}^{-1} \cdot \mathrm{min}^{-1}$ & $51.0(3.6)$ & $40.1(0.7) *$ \\
\hline
\end{tabular}

*Significantly different than men $(p<.05)$. 
maximal oxygen uptake $\left(\mathrm{VO}_{2 \max }\right)$. After a 3-min warm-up they began cycling at $70 \mathrm{~W}$, with increments of $35 \mathrm{~W}$ occurring every $3 \mathrm{~min}$. Verbal encouragement was provided to ensure maximal effort. Expired-gas samples were collected in Douglas bags (Harvard Apparatus, Edenbridge, UK) during the third minute of each work-rate increment, and heart rate was measured continuously using short-range radio telemetry (Polar Beat, Polar Electro Oy, Kempele, Finland). An oxygen/ carbon dioxide analyzer (Servomex 1400, Crowbridge, UK) was used along with a dry gas meter (Harvard Apparatus) to determine $\mathrm{VO}_{\mathrm{E}}, \mathrm{VO}_{2}$, and $\mathrm{VCO}_{2}$. From the $\mathrm{VO}_{2}$-work-rate relationship the work rate equivalent to $65 \% \mathrm{VO}_{2 \max }$ was interpolated. On a second occasion participants completed a familiarization trial. The purpose of this was to familiarize them with the exercise protocol and to verify that the correct relative exercise intensity was being performed. Participants cycled at a constant work rate corresponding to $65 \% \mathrm{VO}_{2 \max }$ for $2 \mathrm{hr}$. Expired-gas samples were collected over a 1-min period into Douglas bags after 10 min and 30 min of exercise and every 30 min thereafter. Heart rate and rating of perceived exertion (RPE) were also measured every $15 \mathrm{~min}$. During this trial the participants were familiarized with the saliva-collection procedure. This enabled them to feel comfortable with the collection method and to establish individual flow rates and an appropriate collection time to ensure that an adequate volume $(\sim 1 \mathrm{ml})$ of saliva was collected for analysis.

\section{Experimental Procedures}

In a randomized crossover design, participants performed two exercise trials separated by at least 1 week. They reported to the laboratory at 9 a.m. after an overnight fast (10-12 hr). A resting fingertip blood sample was obtained using an autoclick lancet, and blood glucose concentration was analyzed in singular using an Accutrend GC (Roche, Germany) glucose analyzer (reported coefficient of variability $3 \%$ ). This was to assess whether the participants were in a fasted state before beginning the trial. Participants then consumed either three cereal bars and $500 \mathrm{ml}$ of a commercially available sports drink (FED; total energy content 2,210 $\mathrm{kJ}$ ) or $500 \mathrm{ml}$ of a dilute low-calorie cordial drink (FAST; total energy content 60 kJ) $2 \mathrm{hr}$ before exercise, because this timing of food and fluid intake is typically recommended for individuals engaging in strenuous physical activity (Williams \& Serratosa, 2006). The nutritional content of the meal is outlined in Table 2. The participants were required to consume the meal within a $15-\mathrm{min}$ time period. They

Table 2 Nutritional Information for the Sports Drink and Cereal Bar

\begin{tabular}{lcc}
\hline Variable & Sports drink $\mathbf{( 5 0 0} \mathbf{~ m l )}$ & Cereal bar $\mathbf{( 3 7} \mathbf{~ g )}$ \\
\hline Energy $(\mathrm{kJ})$ & 590 & 540 \\
Protein $(\mathrm{g})$ & - & 4 \\
Carbohydrate $(\mathrm{g})$ & 32 & 67 \\
Fat $(\mathrm{g})$ & - & 8 \\
Sodium $(\mathrm{mg})$ & 250 & 250 \\
\hline
\end{tabular}


then rested for $1 \mathrm{hr}$ and $45 \mathrm{~min}$ before performing $2 \mathrm{hr}$ of cycling at $65 \% \mathrm{VO}_{2 \max }$ on a stationary cycle ergometer. The order of the trials was randomized. Body mass was measured pre- and postexercise. Heart rate and RPE were obtained at 15-min intervals during exercise, and expired-gas samples were collected every 30 min during exercise using a Douglas bag. Saliva samples were obtained on arrival at the laboratory (baseline), immediately preexercise, $5 \mathrm{~min}$ before cessation of exercise, immediately postexercise, and $1 \mathrm{hr}$ postexercise. Water ingestion was permitted ad libitum before, during, and after exercise with the exception of the 10-min period before each saliva-sample collection. During both experimental trials, the participants were instructed to remain fasted until the 1-hr-postexercise sample had been collected. For the $24 \mathrm{hr}$ preceding each trial, the participants were asked to follow the same (pretrial 1) diet and eating schedule before the subsequent trial. They were also instructed to abstain from alcohol, caffeine, and heavy exercise for $48 \mathrm{hr}$ before each trial. The environmental conditions in the laboratory were $25.4 \pm 0.2{ }^{\circ} \mathrm{C}$ and relative humidity of $41 \% \pm 2 \%$.

\section{Saliva Collection}

Saliva collections were made with the participants seated, leaning forward, with their heads tilted down. Participants were instructed to swallow to empty the mouth before an unstimulated whole saliva sample was collected over a predetermined time period into a preweighed, sterile vial. Care was taken to allow saliva to dribble into the collecting tubes making minimal orofacial movement. Samples were then stored at $-80{ }^{\circ} \mathrm{C}$ until analysis. Saliva volume was estimated by weighing to the nearest milligram, and the saliva density was assumed to be $1.0 \mathrm{~g} / \mathrm{ml}$ (Cole \& Eastoe, 1988). Saliva flow rate ( $\mathrm{ml} / \mathrm{min}$ ) was determined by dividing the volume of saliva by the collection time.

\section{Saliva Analysis}

After thawing, s-IgA concentration was determined by an enzyme-linked immunosorbent assay (ELISA) as described previously by Li and Gleeson (2004). Salivary cortisol was analyzed using a commercially available ELISA kit (DX-SLV2930, DRG Instruments, Marburg, Germany). Osmolality was determined using a cryoscopic (freezing-point depression) osmometer (Osmomat 030, Gonotec, $\mathrm{GbBH}$, Berlin, Germany) calibrated with $300-\mathrm{mOsmol} / \mathrm{kg} \mathrm{NaCl}$ solution. The s-IgA secretion rate was calculated by multiplying the saliva flow rate by the s-IgA concentration. The intra-assay coefficients of variation for the analytical methods were $7.0 \%$ and $3.9 \%$ for s-IgA and cortisol assays, respectively.

\section{Statistical Analysis}

Results are presented as mean and standard error of the mean $( \pm S E M)$. Data were checked for normality, homogeneity of variance, and sphericity before statistical analysis. The salivary data were examined using a three-factor (Trial $\times$ Gender $\times$ Time) repeated-measures ANOVA. Significant differences were assessed using Student's paired $t$ test with Holm-Bonferroni adjustments for multiple comparisons. Physiological variables and RPE were examined using Student's paired $t$ tests. Statistical significance was accepted at $p<.05$. 


\section{Results}

\section{Physiological Variables and RPE}

Mean blood glucose values recorded at baseline were $4.4 \pm 0.3 \mathrm{mmol} / \mathrm{L}$ on the treatment days. Results for exercise intensity $\left(\% \mathrm{VO}_{2 \max }\right)$, heart rate, RPE, body-mass changes, and respiratory-exchange ratio are presented in Table 3. Respiratoryexchange ratio was significantly lower in FAST than in FED $(p<.01)$, but there were no differences between trials in any of the other physiological variables.

\section{Salivary Variables}

Gender did not influence the salivary responses to exercise. However, a significant main effect of condition was observed in s-IgA concentration, s-IgA secretion rate, and osmolality, which were significantly lower in women than in men $(p<$ .01 ; Table 4), but there were no differences between genders in saliva flow rate, s-IgA:osmolality ratio, and cortisol.

Saliva flow rate showed an initial increase from baseline to preexercise. It then decreased significantly during exercise and returned to baseline at $1 \mathrm{hr}$ postexercise, main effect of time $F(3,42)=14.4, p<.001$. There was no effect of FED or FAST on this response (Figure 1[a]).

s-IgA concentration increased with exercise-main effect of time $F(3,34)=$ $8.4, p<.01$ - but there was no effect of FED or FAST on this response (Figure $1[\mathrm{~b}])$. The s-IgA secretion rate did not change significantly throughout the exercise protocol (Figure 1[c]).

Salivary osmolality increased with exercise, main effect of time $F(3,22)=$ $26.9, p<.001$. Salivary IgA:osmolality ratio decreased postexercise, main effect of time $F(3,40)=14.0, p<.001$. There was no effect of FED or FAST on these responses (Table 5).

Salivary cortisol increased postexercise compared with preexercise-main effect of time $F(1,13=7.7), p=.016$-but there was no effect of FED or FAST on this response: preexercise $10.4 \pm 2.2$ versus $9.4 \pm 1.4 \mathrm{nmol} / \mathrm{L}$, postexercise 16.6 \pm 3.7 versus $16.6 \pm 3.8 \mathrm{nmol} / \mathrm{L}$ for FED and FAST trials, respectively.

\section{Table 3 Physiological Variables and RPE Obtained During Each Trial, $N=16, M$ (SEM)}

\begin{tabular}{lcc}
\hline & Fed & Fasted \\
\hline$\% \mathrm{VO}_{2 \max }$ & $65.8(0.7)$ & $65.1(0.9)$ \\
Heart rate, beats/min & $154(3)$ & $151(3)$ \\
Rating of perceived exertion & $12(1)$ & $12(1)$ \\
Body-mass change, $\mathrm{kg}$ & $-0.2(0.2)$ & $-0.2(0.2)$ \\
Fluid intake, $\mathrm{L}$ & $1.20(0.12)$ & $1.27(0.15)$ \\
Fluid loss, $\mathrm{L}$ & $1.41(0.16)$ & $1.49(0.18)$ \\
Respiratory-exchange ratio & $0.94(0.01)$ & $0.91(0.01)^{* *}$ \\
\hline
\end{tabular}

\footnotetext{
**Significantly different than fed $(p<.01)$.
} 
Table 4 Effect of Gender on Salivary Variables at Baseline, M (SEM)

\begin{tabular}{lcc}
\hline & Men, $\boldsymbol{n}=\mathbf{8}$ & Women, $\boldsymbol{n}=\mathbf{8}$ \\
\hline Saliva flow rate, $\mathrm{ml} / \mathrm{min}$ & $0.39(0.45)$ & $0.36(0.71)$ \\
S-IgA concentration, $\mathrm{mg} / \mathrm{L}$ & $224(38)$ & $116(20)^{* *}$ \\
S-IgA secretion rate, $\mu \mathrm{g} / \mathrm{min}$ & $85(14)$ & $41(12)^{* *}$ \\
Osmolality, mOsmol/kg & $94(11)$ & $47(5)^{* *}$ \\
S-IgA:osmolality & $2.4(0.3)$ & $2.5(0.4)$ \\
Cortisol, nmol/L & $8.0(1.8)$ & $12.0(2.7)$ \\
\hline
\end{tabular}

Note. $\mathrm{s}-\mathrm{Ig} \mathrm{A}=$ salivary immunoglobulin $\mathrm{A}$.

**Significantly different than men $(p<.01)$.

\section{Discussion}

The main findings of the study were that prior nutritional status had no influence on the s-IgA response to prolonged cycling. In addition, lower values of s-IgA concentration, s-IgA secretion rate, and salivary osmolality were observed in women than in men at rest, with no effect on the acute responses to exercise.

It has been previously reported that fasting saliva samples yield higher and more variable s-IgA concentrations than nonfasting samples at rest (Gleeson et al., 1990; Gleeson, Pyne, \& Callister, 2004). However, the current results do not support these findings in that s-IgA was not significantly affected by the preexercise nutritional status, and, in fact, s-IgA concentration in the fed state tended to be higher. Furthermore, the data spreads - highlighted by the SEM - for this group of individuals under the two conditions were very similar. It is possible that the discrepant findings might be partly explained by hydration status, because dehydration can reduce the saliva flow rate, which might artificially increase s-IgA concentration (Bishop et al., 2000; Walsh et al., 2002; Walsh et al., 2004). Gleeson et al. (1990) did not report the saliva flow rate or the amount of fluid ingested between conditions; therefore, it is not known whether the higher and more variable levels in s-IgA concentration observed in fasting saliva had been influenced by this factor. Furthermore, the timing of the meal might be a factor because previous studies have shown that mastication (chewing) can stimulate the saliva flow rate up to threefold (Hector \& Linden, 1999) and result in a lower s-IgA concentration recorded immediately afterward (Proctor \& Carpenter, 2001). However, the current results show that ingesting a high- $\mathrm{CHO}$ meal $2 \mathrm{hr}$ before exercise compared with a fasted state has no significant influence on the flow rate or composition of saliva at rest or after exercise.

$\mathrm{CHO}$ is known to attenuate the cortisol response compared with placebo during prolonged exercise (Gleeson, Nieman, \& Pedersen, 2004). However, several studies have shown no effect of $\mathrm{CHO}$ feeding during exercise on s-IgA concentration or secretion rate (Bishop et al., 2000; Nehlsen-Cannarella et al., 2000; Nieman et al., 2002). In the current study salivary cortisol increased postexercise, but there was no effect of nutritional status on this response. Because the inhibition of s-IgA transport (and synthesis) has been previously attributed to increased levels of circulating stress hormones including cortisol (Hucklebridge, Clow, \& 
(a)

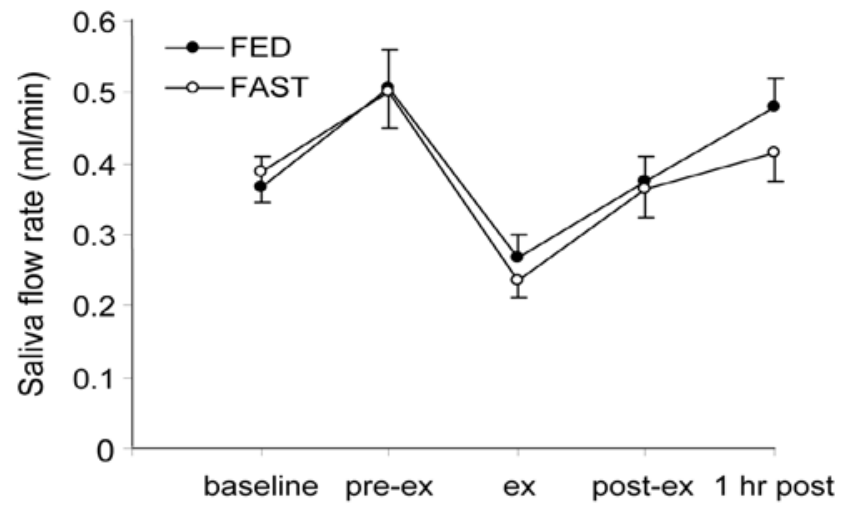

(b)

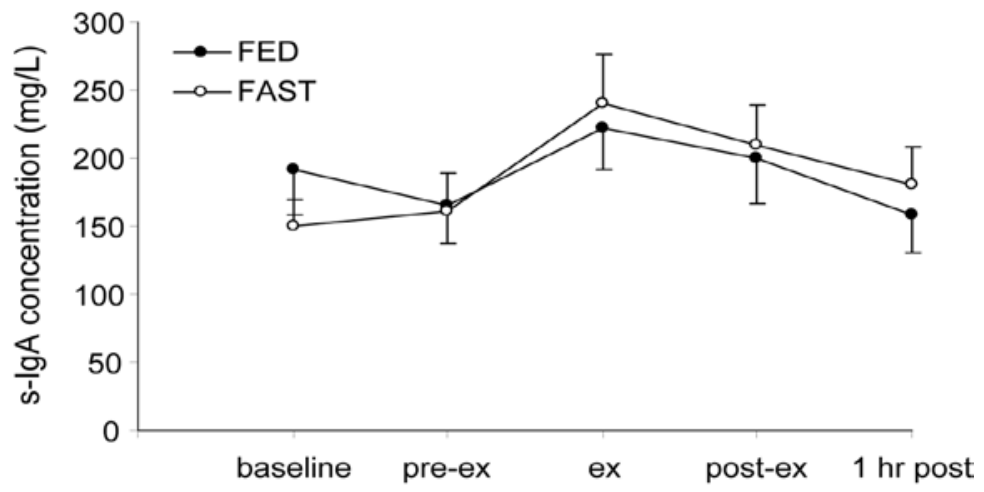

(c)



Figure 1 - The effect of a fed (FED) or fasted (FAST) state on (a) saliva flow rate, (b) s-IgA concentration, and (c) s-IgA secretion responses to exercise. Values are $M \pm S E M(N$ = 16). Note. $\mathrm{s}-\mathrm{Ig} \mathrm{A}=$ salivary immunoglobulin $\mathrm{A}$. 


\section{Table 5 Effect of Fed or Fasted State on Salivary Osmolality and s-IgA:Osmolality, $n=16, M$ (SEM)}

\begin{tabular}{lccccc}
\hline & Baseline & Preexercise & Exercise & Postexercise & $\begin{array}{c}\mathbf{1} \mathbf{~ h r} \\
\text { postexercise }\end{array}$ \\
\hline $\begin{array}{l}\text { Osmolality, } \\
\text { mOsmol/kg } \\
\text { fed }\end{array}$ & & & & & \\
$\quad \begin{array}{l}\text { fasted } \\
\text { s-IgA:osmolality }\end{array}$ & $64(12)$ & $71(8)$ & $144(21)$ & $148(23)$ & $69(9)$ \\
ratio & & $66(8)$ & $152(25)$ & $152(24)$ & $73(11)$ \\
$\quad$ fed & & & & \\
$\quad$ fasted & $2.6(0.3)$ & $2.2(0.2)$ & $1.7(0.2)$ & $1.5(0.2)$ & $2.4(0.4)$ \\
\hline
\end{tabular}

Note. $\mathrm{s}-\mathrm{Ig} \mathrm{A}=$ salivary immunoglobulin $\mathrm{A}$.

Evans, 1998; Sabbadini \& Berczi, 1995), this might explain in part why no differences in the s-IgA response were observed between the two conditions.

The significant reduction in saliva flow rate with exercise observed in this study is consistent with many previous studies (Blannin et al., 1998; Mackinnon \& Jenkins, 1993; Steerenberg et al., 1997; Walsh et al., 2002). Salivary secretion is predominantly under the control of the autonomic nervous system (Chicharro et al., 1998) and depends on both parasympathetic cholinergic nerves and sympathetic adrenergic nerves. It is now accepted that the reduction in saliva flow rate associated with exercise results in part from a removal of parasympathetic vasodilatory influences rather than sympathetic vasoconstriction because only sympathetic secretomotor rather than vasoactive nerve fibers are activated under reflex conditions (Proctor \& Carpenter, 2007). Indeed, the saliva flow rate was lowest at the sample point during exercise when parasympathetic activity would be largely inhibited and began to recover on cessation of exercise ( 5 min after). It has been reported that dehydration has the greatest negative impact on saliva flow rate during exercise (Walsh et al., 2004), which tends to occur after losses of $~ 3 \%$ body mass. In the current investigation only small changes in body mass occurred postexercise $(\sim 0.5 \%)$, and despite this, a decrease in saliva flow rate and an increase in osmolality were still observed. These findings contrast with those of Bishop et al. (2000) and Walsh et al. (2004), in which fluid intake (to match predetermined sweat losses in the latter study) prevented the decrease in flow rate and increase in osmolality, which might suggest a greater effect of neural activation on saliva flow rate and electrolyte secretion during exercise rather than dehydration per se. This might bring into question their sensitivity as indicators of hydration status after exercise. It is noteworthy that an initial increase in the saliva flow rate from baseline to preexercise $2 \mathrm{hr}$ later was observed, which might be a result of diurnal variation, because saliva flow rate tends to increase throughout the day (Dawes, 1974). On the other hand, it might relate to an anticipatory increase in sympathetic activity and inhibition of parasympathetic activity, which would reduce the saliva flow rate (Blannin et al.). 
Salivary IgA concentration increased significantly with exercise, which is in accordance with many previous studies involving prolonged cycling (Blannin et al., 1998; Li \& Gleeson, 2004; Walsh et al., 2002). This is likely because of the reduction in saliva flow rate and slight dehydration, rather than genuine alterations in the mucosal immune response (Walsh et al., 2002), because s-IgA secretion rate did not change significantly throughout the exercise protocol. Many previous studies have reported significant reductions in s-IgA secretion rate after prolonged cycling (Laing et al., 2005; Mackinnon, Chick, Van, \& Tomasi, 1989; Walsh et al., 2002). Although s-IgA secretion rate did not change significantly with exercise in the current study, a 30\% reduction was observed during exercise compared with preexercise. Whether this trend has any physiological significance in terms of risk of infection, however, is unknown. Despite no significant change in the s-IgA secretion rate with exercise, a clear significant reduction in the s-IgA:osmolality ratio was observed, which returned to baseline levels at $1 \mathrm{hr}$ postexercise, and this is in accordance with findings by Laing et al. A reduction in the s-IgA:osmolality ratio postexercise lends some support to a transient depression of mucosal immunity postexercise, which recovers to baseline levels after $1 \mathrm{hr}$ of rest. However, because significant reductions in the other measures of s-IgA were not demonstrated, this highlights the continued uncertainty over which measure to use when investigating the effects of exercise on mucosal immune function.

Striking gender differences were observed in that resting s-IgA concentration, s-IgA secretion rate, and osmolality in women were approximately half those of men. Previous studies have reported a lower s-IgA concentration in females at rest (Evans et al., 2000; Gleeson et al., 1999), although Nieman et al. (2002) found no gender differences in s-IgA concentration or secretion rate during a marathon race. Although there was no effect of gender on the acute response to exercise, a significant difference in resting saliva composition might have practical importance if these parameters are to be used as predictors of infection risk or as a marker of hydration status in athletes. If laboratories are to establish clinically relevant ranges, such differences would need to be considered. The physiological significance of these differences is yet to be elucidated. Sex hormones are known to play a role in the immune system at rest (Timmons, Hamadeh, Devries, \& Tarnopolsky, 2005). However, Burrows, Bird, and Bishop (2002) found no differences in s-IgA in a group of highly trained female endurance athletes over the menstrual cycle. Moreover, there was no relationship between s-IgA concentration and progesterone. It is possible that absolute training status (weight-specific $\mathrm{VO}_{2 \max }$ was $20 \%$ lower in women) might have influenced these values, because a higher s-IgA concentration has been previously reported in elite athletes than in either active or sedentary individuals (Francis, Gleeson, Pyne, Callister, \& Clancy, 2005). Furthermore, because a dietary analysis of the participants was not conducted, it is not known whether the differences were related to deficiencies in certain nutrients such as protein (Chandra, 1997; Gleeson, Pyne, \& Callister, 2004). The finding of lower levels of mucosal immunity in women than in men in this study contrasts with reports that females appear to be more resistant to viral infections in the general population (Beery, 2003). Thus, further research is warranted to investigate s-IgA between genders in different athletic populations and to determine the importance of such differences in infection risk.

In summary, the results of the current study show that exercise performed in either a fed or a short-term ( 10-hr) fasted state appears to have little influence on 
the response pattern of s-IgA and salivary cortisol during prolonged, strenuous exercise. In addition, these results demonstrate lower levels of resting s-IgA and osmolality in women than in men, with no effect on the acute response to exercise.

\section{References}

Allgrove, J.E., Gomes, E., Hough, J., \& Gleeson, M. (2008). Effect of exercise intensity on salivary antimicrobial proteins and markers of stress in active men. Journal of Sports Sciences, 26, 653-661.

Beery, T.A. (2003). Sex differences in infection and sepsis. Critical Care Nursing Clinics of North America, 15, 55-62.

Bishop, N.C., Blannin, A.K., Armstrong, E., Rickman, M., \& Gleeson, M. (2000). Carbohydrate and fluid intake affect the saliva flow rate and IgA response to cycling. Medicine and Science in Sports and Exercise, 32, 2046-2051.

Blannin, A.K., Robson, P.J., Walsh, N.P., Clark, A.M., Glennon, L., \& Gleeson, M. (1998). The effect of exercising to exhaustion at difficult intensities on saliva immunoglobulin A, protein and electrolyte secretion. International Journal of Sports Medicine, 19, 547-552.

Burrows, M., Bird, S.R., \& Bishop, N. (2002). The menstrual cycle and its effect on the immune status of female endurance runners. Journal of Sports Sciences, 20, 339344.

Chandra, R.K. (1997). Nutrition and the immune system: An introduction. The American Journal of Clinical Nutrition, 66, 460S-463S.

Chicharro, J.L., Lucia, A., Perez, M., Vaquero, A., \& Urena, R. (1998). Saliva composition and exercise. Sports Medicine (Auckland, N.Z.), 26, 17-27.

Cole, A.S., \& Eastoe, J.E. (1988). Biochemistry and oral biology (2nd ed., pp. 476-477). London: Wright.

Dawes, C. (1974). Rhythms in salivary flow rate and composition. International Journal of Chronobiology, 2, 253-279.

Evans, P., Derm, G., Ford, G., Hucklebridge, F., Hunt, K., \& Lambert, S. (2000). Social class, sex, age differences in mucosal immunity in a large community sample. Brain, Behavior, and Immunity, 14, 41-48.

Fahlman, M.M., \& Engels, H.J. (2005). Mucosal IgA and URTI in American college football players: A year longitudinal study. Medicine and Science in Sports and Exercise, 37, 374-380.

Francis, J.L., Gleeson, M., Pyne, D.B., Callister, R., \& Clancy, R. (2005). Variation of salivary immunoglobulins in exercising and sedentary populations. Medicine and Science in Sports and Exercise, 37, 571-578.

Gleeson, M. (2007). Immune function in sport and exercise. Journal of Applied Physiology, 103, 693-699.

Gleeson, M., \& Bishop, N.C. (2000). Elite athlete immunology: Importance of nutrition. International Journal of Sports Medicine, 21, S44-S50.

Gleeson, M., Cripps, A.W., Clancy, R.L., \& Geraghty, S.B. (1990). The variability of immunoglobulins and albumin in saliva of normal and IgA-deficient adults. In T.T. McDonald (Ed.), Advances in mucosal immunology (pp. 500-501). Lancaster, UK: Kluwer Academic.

Gleeson, M., McDonald, W.A., Pyne, D.B., Cripps, A.W., Francis, J.L., Fricker, P.A., et al. (1999). Salivary IgA levels and infection risk in elite swimmers. Medicine and Science in Sports and Exercise, 31, 67-73.

Gleeson, M., Nieman, D.C., \& Pedersen, B.K. (2004a). Exercise, nutrition and immune function. Journal of Sports Sciences, 22, 115-125.

Gleeson, M., Pyne, D.B., \& Callister, R. (2004b). The missing links in exercise effects on mucosal immunity. Exercise Immunology Review, 10, 107-128. 
Hector, M.P., \& Linden, R.W.A. (1999). Reflexes of salivary secretion. In J.R. Garrett, J. Ekstrom, \& L.C. Anderson, eds., Neural mechanisms of salivary gland secretion. Frontiers in oral biology, Vol. 11 (pp. 196-218). Basel, Switzerland, Karger.

Hucklebridge, F., Clow, A., \& Evans, P. (1998). The relationship between salivary secretory immunoglobulin A and cortisol: Neuroendocrine response to awakening and the diurnal cycle. International Journal of Psychophysiology, 31, 69-76.

Laing, S.J., Gwynne, D., Blackwell, J., Williams, M., Walters, R., \& Walsh, N.P. (2005). Salivary $\operatorname{IgA}$ response to prolonged exercise in a hot environment in trained cyclists. European Journal of Applied Physiology, 93, 665-671.

Lamm, M.E. (1998). Current concepts in mucosal immunity. IV. How epithelial transport of IgA antibodies relates to host defense. The American Journal of Physiology, 274(4 Pt. 1), G614-G617.

Li, T.L., \& Gleeson, M. (2004). The effect of single and repeated bouts of prolonged cycling and circadian variation on saliva flow rate, immunoglobulin A and $\alpha$-amylase responses. Journal of Sports Sciences, 22, 1015-1024.

Mackinnon, L.T. (2000). Chronic exercise training effects on immune function. Medicine and Science in Sports and Exercise, 32, S369-S376.

Mackinnon, L.T., Chick, T.W., Van, A.S., \& Tomasi, T.B. (1989). Decreased secretory immunoglobulins following intense endurance exercise. Sports Training and Medical Rehabilitation, 1, 209-218.

Mackinnon, L.T., \& Hooper, S. (1994). Mucosal (secretory) immune system responses to exercise of varying intensity and during overtraining. International Journal of Sports Medicine, 15, S179-S183.

Mackinnon, L.T., \& Jenkins, D.G. (1993). Decreased salivary IgA after intense interval exercise before and after training. Medicine and Science in Sports and Exercise, 25, 678-683.

McDowell, S.L., Chaloa, K., Housh, T.J., Tharp, G.D., \& Johnson, G.O. (1991). The effect of exercise intensity and duration on salivary immunoglobulin A. European Journal of Applied Physiology, 63, 108-111.

Nehlsen-Cannarella, S.L., Nieman, D.C., Fagoaga, O.R., Kelln, W.J., Shannon, M., \& Davis, J.M. (2000). Saliva immunoglobulins in elite women rowers. European Journal of Applied Physiology, 81, 222-228.

Neville, V., Gleeson, M., \& Folland, J.P. (2008). Salivary IgA as a risk factor for upper respiratory infections in elite professional athletes. Medicine and Science in Sports and Exercise, 40, 1228-1236.

Nieman, D.C., Henson, D.A., Fagoaga, O.R., Utter, A.C., Vinci, D.M., Davis, J.M., et al. (2002). Change in salivary IgA following a competitive marathon race. International Journal of Sports Medicine, 23, 69-75.

Nieman, D.C., Johanssen, L.M., Lee, J.W., \& Arabatzis, K. (1990). Infectious episodes in runners before and after the Los Angeles Marathon. Journal of Sports Medicine and Physical Fitness, 30, 316-328.

Oliver, S.J., Laing, S.J., Wilson, S., Bilzon, J.L., Walters, R., \& Walsh, N.P. (2007). Salivary immunoglobulin A response at rest and after exercise following a $48 \mathrm{~h}$ period of fluid and/or energy restriction. The British Journal of Nutrition, 97, 1109-1116.

Peters, E.M., \& Bateman, E.D. (1983). Ultramarathon running and upper respiratory tract infections. South African Medical Journal. Suid-Afrikaanse Tydskrif Vir Geneeskunde, 64, 582-584.

Proctor, G.B., \& Carpenter, G.H. (2001). Chewing stimulates secretion of human salivary secretory immunoglobulin A. Journal of Dental Research, 80, 909-913.

Proctor, G.B., \& Carpenter, G.H. (2007). Regulation of salivary gland function by autonomic nerves. Autonomic Neuroscience: Basic \& Clinical, 30(133), 3-18.

Rantonen, P.J., \& Meurman, J.H. (2000). Correlations between total protein, lysozyme, immunoglobulins, amylase, and albumin in stimulated whole saliva during daytime. Acta Odontologica Scandinavica, 58, 160-165. 
Sabbadini, E., \& Berczi, I. (1995). The submandibular gland: A key organ in the neuroimmuno-regulatory network? Neuroimmunomodulation, 2, 184-202.

Sari-Sarraf, V., Reilly, T., Doran, D., \& Atkinson, G. (2007). The effects of single and repeated bouts of soccer-specific exercise on salivary IgA. Archives of Oral Biology, 52, 526-532.

Saxon, A., Stevens, R.H., Ramer, S.J., \& Clements, P.J. (1978). Glucocorticoids administered in vivo inhibit suppressor T lymphocyte function and diminish B lymphocyte responsiveness in in vitro immunoglobulin synthesis. The Journal of Clinical Investigation, 61, 922-930.

Spence, L., Brown, W.J., Pyne, D.B., Nissen, M.D., Sloots, T.P., McCormack, J.G., et al. (2007). Incidence, etiology, and symptomatology of upper respiratory illness in elite athletes. Medicine and Science in Sports and Exercise, 29, 577-586.

Steerenberg, P.A., Van Asperen, I.A., Van Nieuw Amergongen, A., Biewenga, J., Mol, D., \& Medema, G. (1997). Salivary levels of immunoglobulin A in triathletes. European Journal of Oral Sciences, 105, 305-309.

Tenovuo, J. (1998). Antimicrobial function of human saliva-How important is it for oral health? Acta Odontologica Scandinavica, 56, 250-256.

Timmons, B.W., Hamadeh, M.J., Devries, M.C., \& Tarnopolsky, M.A. (2005). Influence of gender, menstrual phase, and oral contraceptive use on immunological changes in response to prolonged cycling. Journal of Applied Physiology, 99, 979-985.

Tomasi, T.B., Trudeau, F.B., Czerwinski, D., \& Erredge, S. (1982). Immune parameters in athletes before and after strenuous exercise. Journal of Clinical Immunology, 2, $173-178$.

Walsh, N.P., Bishop, N.C., Blackwell, J.B., Wierzbicki, S.G., \& Montague, J.C. (2002). Salivary IgA response to prolonged exercise in a cold environment in trained cyclists. Medicine and Science in Sports and Exercise, 34, 1632-1637.

Walsh, N.P., Blannin, A.K., Clark, A.M., Cook, L., Robson, P.J., \& Gleeson, M. (1999). The effects of high intensity intermittent exercise on saliva IgA, total protein and alpha-amylase. Journal of Sports Sciences, 17, 129-134.

Walsh, N.P., Laing, S.J., Oliver, S.O., Montague, J.C., Walters, R., \& Bilzon, J.L. (2004). Saliva parameters as potential indices of hydration status during acute dehydration. Medicine and Science in Sports and Exercise, 36, 1535-1542.

Williams, C., \& Serratosa, L. (2006). Nutrition on match day. Journal of Sports Sciences, 24, 687-697. 